\title{
Science, religion and the need for a world-view
}

\author{
Lars Haikola ${ }^{1}$ \\ Blekinge Institute of Technology, Karlskrona (Sweden) \\ Visiting Professor: University of Pretoria
}

\begin{abstract}
This article maintains that humankind is in need of a world-view and that traditionally, this need was fulfilled by myth and religion. The mechanistic world-view was created as a result of the breakthrough in science in the $17^{\text {th }}$ century. Early Christianity reacted to science by including the new scientific knowledge as part of religious knowledge. This reaction was formulated within Natural Theology and the Design Argument. After Darwin, when the Design Argument became implausible, science and religion were defined as two different realms or jurisdictions. Today, the new physics has created new scientific knowledge which undermines the mechanistic world-view. Despite this fact, a new world-view has not emerged and this can be attributed to the status of science having changed, rather than to a new content in science.
\end{abstract}

\section{INTRODUCTION}

Albert Einstein once said: "Religion without science is blind. Science without religion is lame." When the Nobel laureate in physics, Max Planck, celebrated his 60th birthday, Einstein honoured him with a speech about the principles of science. Einstein maintained that it is every man's aim to create a picture of the world for himself. Such picture would, of necessity, be simplified and perspicuous, since its purpose is to replace the real and complex world. According to

\footnotetext{
${ }^{1}$ Dr Lars Haikola, Professor in Philosophy and Religion and Vice-Chancellor of the Blekinge Institute of Technology in Karlskrona (Sweden) visited the Faculty of Theology at the University of Pretoria in March 2003 as guest of Prof Dr I W C van Wyk (Hervormde Teologiese Opleiding), Prof Dr T F J Dreyer (Hervormde Teologiese Kollege), and Prof Dr A P B Breytenbach, Deputy Dean of the Faculty of Theology. This article was presented at the Faculty of Theology during Prof Haikola's visit to the University of Pretoria.
} 
Einstein (1934), it is not only the scientist that strives towards achieving this goal, but so too the painter, the poet, and the philosopher.

Einstein is just one of many who maintain that man is curious by nature and puts questions to the natural world. It is this distinguishing characteristic that has driven man to continuously seek and organise knowledge. We all, in different ways, try to find a firm foundation that could serve as a ground, not only for our theoretical comprehension of the world, but also for our emotional faculties. Einstein suggests that man has a need to organise the world in order to feel safe and secure. And this order is created not only by scientists, but by all kinds of people: painters, poets and philosophers.

In this article, I will deal with the classical problem of science and religion in the following way:

- As Einstein suggests, man has a need for a world-view and many examples in literature attest to this basic thesis.

- The concept of a world-view must be clarified, mainly through stipulation and in this regard, a comparison with the classical myth is illuminative.

- Science (namely natural science) once constituted a firm foundation for such a world-view, often called the mechanistic world-view.

- The immediate reactions to the scientific revolution were formulated in Natural Theology and the Design Argument.

- It was not until after Darwin that the reduction of religion set in and the relation between science and religion was declared as being that of two jurisdictions.

- Today, the mechanistic world-view has waned. There is a new content in science and it (science) enjoys a new status yet, there is no new, scientifically based world-view. How should this be explained? 


\section{THE NEED FOR A WORLD-VIEW: SOME EXAMPLES}

James Fowler, a well-known psychologist of religion, introduced the concept of homo poeta (man, the meaning maker). "We do not live by bread alone, sex alone, success alone, and certainly not by instinct alone. We require meaning. We need purpose and priorities; we must have some grasp of the whole picture" (Fowler 1981:4). This can be seen as a variation of Durkheim's classical definition of religion in which he emphasises that the function of religion is to constitute an order that makes reality understandable to the individual and to explain the individual person's position in life.

The theoretical physicists, David Bohm and David Peat, maintain that in ancient times, man had a cosmic dimension that enabled him to feel and comprehend reality as a whole. This cosmic need was initially satisfied by living in harmony with nature, and later on by living in harmony with religion. The prime task of religion, according to Bohm and Peat (1989:254), is to "define the wholeness" and to put man into this wholeness.

In his famous book Chance and necessity, another well-known scientist and Nobel laureate for the discovery of the genetic code, Jacques Monod, states that "man has an inherited need for some kind of world-view and that this need is written somewhere in the language of the genetic code" (Monod 1970). Monod is among scientists indeed the most emphatic about a comprehensive world-view as being a human need. For Monod this is not a cultural concept, but something we all bear in our genes!

Thus, when dealing with this matter, we are not only hearing the voice of scholars in psychology, sociology or other disciplines in the humanities or the social sciences. Einstein, Bohm, Monod, and others represent examples of scientists calling for some kind of explanatory pattern of reality, which would make that reality understandable. Let us then call this explanatory pattern, for which there is a common quest, a world-view. 


\section{WORLD-VIEW AND MYTH}

The concept world-view is not well defined. It is pointless to attempt defining the concept in itself, but there is nonetheless a need for a rudimentary description, in the sense of providing some stipulation of the concept.

\subsection{Does everybody have a world-view?}

It can be argued with good reason that everybody, including atheists, has a world-view. However, the world-view is not necessarily clear or explicit to the person embracing it. Most of the time, the basic structure of an individual's worldview crystallises when crises in life, such as disease, divorce, death, etcetera are experienced. The need for a world-view may also arise in the course of the usual crises in life (rites de passage), such as early childhood, adolescence and middle and old age. In the transition from one stage to the next, we usually build and revise the views we hold of life and the world.

\subsection{World-views: Perspective, heuristic, utopian}

The term "view" is symptomatic for the kind of vagueness and openness we are dealing with in connection with world-views. It can be compared with the terms "aspect", "perspective" or "picture". Just as there are many aspects of or perspectives on a matter, so too are many world-views by definition possible. Otherwise, we would have used terms such as "description" or "theory".

World-views are also temporary, tentative and heuristic since they are supposed to never be complete. Every human being's natural curiosity, his tendency to acquire and create new knowledge and to format such knowledge into a new whole, a new structure, form the very foundation of a world-view. However, the jigsaw puzzle is never completed, because that would imply that curiosity has reached an end. This means that a world-view has to include a vision and has to have a utopian character.

\subsection{The descriptive and prescriptive aspects}

There is both a descriptive and a prescriptive aspect to world-view. A world-view provides a description of reality in a general way. It provides a fundamental view 
of what in essence is to be counted as real. For example, the law of causality and the theory of evolution are such general theoretical principles that the validity thereof is presupposed in our world-view.

A world-view also includes fundamental moral convictions and aesthetical values and norms. It includes a basic ethical system that guides us in that which is of utmost value to us.

A world-view is a pattern of reality and life and an instrument with which to interpret and make it (life and reality) understandable. It is an essential tool with which to understand the world and upon which to act in life. A world-view is not only a pattern for interpretation, not only a philosopher's distanced view on reality and life, but is also a pattern for action. Its purpose is to help the individual not only to understand it, but to act in the world. Its ethical component should not merely be known, but is supposed to be put to use.

\subsection{Myth}

We could compare the concept of world-view with the traditional concept of myth. Myth (especially creation-myths) explains how the world is created and why the world looks the way it does. Myth explains "natural" differences, hierarchies and categories; it explains why there are animals and plants, fishes and reptiles. Myth also explains why there is change and development in nature, why trees turn green in springtime, why water flows to the sea. Finally, myth explains the place of man in the universe; it explains existential phenomena such as birth and death, growth and maturity, love and hate.

Myth explains the world by bringing a certain order to the universe. The order of the universe is carried through in the description of hierarchies, changes and existential phenomena. But myth not only describes the world in a certain way, it also states how the world ought to be. Through description and by ordering, myth simultaneously sanctions and legitimises a society, cultural rules, the standing of the individual person, the role of the family, the status of the gods, the exercising of justice, etcetera.

When in the biblical creation story man is said to "fill the earth and subdue it; and have dominion over the fish of the sea and over the birds of the air and 
over every living thing that moves upon the earth", it is a way of marking the world's hierarchy; to show man's position at its pinnacle and to authorise man's right to use fishes, birds and land animals. Thus, the creation myth expresses an order, an order which it explains and sanctions at the same time.

In myth it is vital not to separate fact and value: Because reality is of a certain nature, man ought to act in a certain way. It is this connection that David Hume effectively dissolved in the $18^{\text {th }}$ century. However, in a world-view it has an important role. By providing an explanation, the world-view at the same time sanctions a basic ethical system.

\subsection{Conclusion}

Traditionally, myth and religion satisfied the need for a world-view. For centuries Christianity served as the dominating world-view in the Western world. With the breakthrough of science, a slow process of change set in. An ideology was constructed on the foundation of science and became the mechanistic worldview.

\section{THE MECHANISTIC WORLD-VIEW}

The mechanistic world-view is part of Western cultural heritage and we are all able to easily recognise it. Today, the mechanistic world-view still prevails to a large extent. It has as point of departure the fact that reality is organised and that the universe is a cosmos, not chaos.

In the mechanistic world-view the method by which we acquire knowledge about the world comes from the field of science. When Galileo and Newton established rules with regard to the free fall of bodies, inertia, etcetera, they also laid down a paradigm for attaining knowledge in general. To put it even stronger, in the mechanistic world-view the concept of knowledge means those truths that have been secured by scientific methods.

This method of gaining knowledge includes "putting questions" to nature by experimenting, by seeking a connection between all the answers and, when a connection is found, by formulating the connection as concisely as possible into a 
law of nature, preferably in mathematical form. The final step is to return to nature to verify (or falsify) this physical law by means of additional experiments.

The mechanistic world-view is a consequence of the science of Galileo and Newton. It is characterised by the idea that everything in the world is ruled by causal laws. The Universe is a clockwork and God is the clockmaker. The Universe ultimately consists of small indivisible particles (atoms), which are material in nature. It is these atoms that move and are combined in a way completely regulated by laws and which is therefore predictable. The whole of the Universe, man included, is therefore in principle determined, and determined by the same laws as the rest of nature.

An extreme consequence of the mechanistic world-view is implied by "the demon of Laplace". Laplace suggested that, should ever there exist a demon that would, only once in the history of the universe, have total knowledge of the positions of all particles and all laws of nature (which situation can be likened to pausing the videotape of the universe and to have total knowledge of that picture), then this demon could anticipate all future events and gather all historical events.

This demon will certainly never exist. However, the concept of Laplace's demon also alludes to a naively optimistic aspect of the mechanistic world-view. Thanks to science (it is presupposed) we acquire more and more knowledge about reality and in principle, we are able to attain complete knowledge of the Universe. This is the cumulative ideal of knowledge, which is also a characteristic of the mechanistic world-view. The optimism in the mechanistic world-view later on goes hand in hand with the theory of evolution and has proceeded into modern times proclaiming that science can solve even more problems. Extreme views even claim that science is able to solve any problem of any kind whatsoever.

The way in which Newton looked for and attained knowledge became a paradigmatic model for knowledge acquisition. Much later, the scientific method of acquiring and creating knowledge reached a monopolistic position. The mechanistic world-view, taken to its utmost consequences, proclaims that the 
only way to knowledge is the scientific way, which seems to leave very little room for religion.

\section{NATURAL THEOLOGY AND THE DESIGN ARGUMENT}

During the early beginnings of science Christianity had no problems in accepting science simply by integrating it into its own framework. The prevalent reaction to the early scientific movement was manifested in natural theology. Natural theology implies that man can attain knowledge of God in a natural way that is, by reason and senses, thereby implying that revelation is not an essential means to knowledge of God. Natural theology was both simple and ingenious, maintaining that all those connections and regularities continuously being discovered by scientists serve as arguments, not only for scientific laws and a scientific attitude to reality, but also for religious belief. Science became an activity within religion, since knowledge of God was attained through knowledge of nature, and the more one knew about nature, the more you knew about God.

Science as part of religion must be seen within the context of a teleological universe, from which the name, design argument, is derived. In the design argument, the human eye serves as paradigmatic example: it appears to everybody to be a very complex and an exceedingly adequate structure for its purpose. Often, examples were taken from the life-sciences, but at the same time, occurrences such as the rotation of the globe around its own axis (giving us days for work and nights for rest), the rotation of the earth around the sun (giving us the changes of the seasons), the proportions between water and land (giving us optimal life-conditions), were also put forward as arguments in favour of the thesis that the universe is well adapted to its purpose. This fact thus compels one to draw the conclusion that there is an intelligent creator, God.

This conclusion is drawn by making use of the following analogy. We know that the highly functional instrument, the clock, has an intelligent constructor, the clockmaker. We are able to observe in nature and in the universe many examples of well-functional systems of far more complex nature. These systems, then, must be designed by a far more intelligent designer, God. Every new 
scientific discovery reinforced the thesis of there being an intelligent creator of the universe.

In natural theology there is thus harmony between science and religion. Early science even reinforced religion. This harmony was reached by looking upon science and religion as two different ways of attaining the same body of knowledge. But fundamentally, this knowledge is of a religious character. Early science was cultivated within the garden of religion. Newton himself presents a good example of a scientist in this garden. Many of his works are of a theological, rather than of a purely scientific nature and all his scientific exploring was done to the glory of God. The same is true of the founder of systematic botany, the Swedish scientist Carl von Linné, who wrote "I saw the eternal, omniscient and omnipotent God on his back, where he proceeded and I trembled. I traced his footsteps on the fields of Nature and I noticed in everyone, even in the ones I could hardly discern, an eternal wisdom and power, an inscrutable perfection" (author's translation).

\section{POST-DARWIN THEOLOGY: SCIENCE AND RELIGION AS TWO JURISDICTIONS}

However, after Darwin and the triumph of the evolution theory, natural theology became implausible. The function of the eye could be explained without reference to intervention by God. Thus, the mechanistic world-view affected the field of human sciences as well.

Since the decline of natural theology, the scene changed as a scientific discovery could no longer be integrated into religion. As science expanded and progressed, religious belief withdrew. This withdrawal implied that religious belief relinquished all claims to describe reality, and science monopolised all description of reality. Science, and science only, could offer correct and adequate descriptions and explanations of reality (i e causal explanations).

The overoptimistic view that science could solve all kinds of problems had implications for ethics, aesthetics and religion. In fact, it left very little room for religion. However, this naive optimism regarding progress was far from being accepted by all, even among scientists. There was an opposite view too, which maintained that science could not and should not be applied to all kinds of 
issues. Science is accepted as valid within certain parameters only. As a consequence, a realm with its own parameters was developed for religion, and religious belief acquired a jurisdiction of its own. This jurisdiction was defined in different ways. It could be defined by the unique existential dilemma of the human being, or by the ethical credo of man, or by the individual's relation to God. (Confer in this regard for example the late $19^{\text {th }}$ and early $20^{\text {th }}$ century theologians from Schleiermacher to Moltmann.) This was a decisive moment in the development of religion, because this was the point at which Christianity clearly turned out to be a private matter. An early example of this attitude is reflected in Michael Faraday's famous words: "When I am in the laboratory I leave God outside, but when I enter the prayer room science is not there."

The division into different competencies or jurisdictions received its classical expression in a resolution formulated by The National Academy of Sciences, (USA) in 1972: "Whereas religion and science are, therefore, separate and mutually exclusive realms of human thought whose presentation in the same context leads to misunderstanding of both scientific theory and religious belief."

Religion and science were looked upon as two different and independent areas which, in order to avoid misunderstanding, should not be intermingled. Today, this separation is still valid. In fact, it expresses the standard relation between science and religion and could be regarded as a supplement to the mechanistic world-view.

\section{THE DECLINE OF THE MECHANISTIC WORLD-VIEW}

The mechanistic world-view is deeply embedded and is still alive. But today, there are signs, both of an intra-scientific and an extra-scientific kind, of its dissolution. The scientific foundation, the content of science, has changed and the attitude towards science, as well as its status has changed. There are valid grounds for a new world-view.

\subsection{Intra-scientific reasons}

Vital points in the mechanistic world-view nowadays lack scientific foundation. Today our knowledge regarding the minute particles in the quantum-world that 
constitute the world which Newton saw and the one we see, is completely new. Our knowledge of what the universe looks like from very remote distances, is also totally new. Science has discovered that other types of laws are valid in the micro and macro world. These laws differ from those applicable in the world that Newton was able to observe and measure. During the $20^{\text {th }}$ century knowledge of the micro cosmos and the macro cosmos has expanded dramatically (i e the former through the quantum physics of Heisenberg and Bohr, and the latter through Einstein's theories of relativity).

It is a well-known fact that in the quantum world there are processes which are unpredictable and indeterminable. It is impossible to predict how single particles and certain quanta-systems will behave. The law of cause and effect, which is such a self-evident part of our common sense, fails us. In the world of quanta, spontaneous changes are not only allowed for, but are even inevitable. Although the quantum effects are normally limited to the micro-world of the atoms, the laws of the quantum physics are applicable everywhere. Therefore, chance plays a principally important role in the universe. Causal laws are not universally valid and therefore predictability is not universal. So Laplace was wrong. It is impossible to observe nature without affecting it. Strict objectivity becomes impossible. In the very small world of particles (quarks) the measuring tools are far bigger than the particles they are supposed to measure, so just by applying them to the quarks, changes are effected to the quarks.

According to Heisenberg's uncertainty principle it is not possible to know with unlimited accuracy both the position and the momentum of a particle. One has to focus on either the position or the momentum. This is actually also known as the Principle of Indeterminism. Particles are more adequately described as systems of wave motions or electronic fields. The smallest parts in the universe are not material in character any more, which means that materialism is inadequate.

Time and space do not form the independent background to things and processes. Rather, time is dependent of the velocity of a particle. So, if a particle is moving very, very rapidly, time is squeezed. There is no absolute space and time. 
To conclude, just one of these new discoveries is enough to undermine the mechanistic world-view. However, no new unified world-view has crystallised as a result of the new physics. The process from the $17^{\text {th }}$ and $18^{\text {th }}$ century has not been repeated. Why?

\subsection{Extra-scientific reasons}

We believe that the main reason why the scientific discoveries of the new physics did not found a new world-view in the $20^{\text {th }}$ century is because science did not retain its previous strong position as a social force. The scientific breakthrough of the $17^{\text {th }}$ century truly signified a revolution for mankind. Gradually, the general public could, through all the technical innovations in their daily life, get some confirmation of the reliability of science. The telephone and the steam engine were real and worked and, in a way, attested to the scientific interpretation of the world. Later, the obvious results of medicine had the same effect in "proving" science. Science became one of the strongest operative elements in man's culture. It formed the foundations of a world-view.

\subsubsection{The incompleteness of science}

Science penetrates our culture in such a way that we tend to apprehend reality in a scientific way, and this is valid irrespective of whether or not it is maintained by an explicit ideology of science. However, the basically deterministic natural science has never been able to deal with concepts such as man, mind, soul, good and evil, will, guilt or conscience. The incompleteness of science has become obvious. Science is adequate to explain scientific questions, mainly through causal explanations, but it cannot treat teleological questions - questions of purpose and meaning. Without the ability and the ambition to answer whyquestions, science cannot create meaning in or a goal for human life. Science alone is not an adequate ground for a world-view. Science offers part of, but not enough ground for building a world-view. 


\subsubsection{The relativity of science and models}

The results presented within for instance quantum physics, cosmology or chaostheory, tend to destroy what we have been accustomed to call common sense. By this, science undermines its own monopoly as a description of reality. This, in turn, is connected to the fact that science today makes use of models. It has become an essential feature of modern science and it implies another kind of claim. The decisive criterion in determining whether a model is a good one is ultimately not whether the model is true in any unsophisticated correspondence meaning, but whether the model is simple, prolific and possesses great explanatory power. A relativisation of science has taken place, which means that science is no longer understood as the self-evident and firm foundation it used to be. Models are instruments for understanding reality and instruments are adequate for different purposes.

\subsubsection{The uncertainty of science}

Earlier science guaranteed the true description and explanation of the world. The scientific method was a revolution in the progress of knowledge. Today, there is a nimbus of uncertainty in science, not only for the reason mentioned above, namely that scientific truth is an instrumental truth, but also in a more common sense. In, for example, the debate about environmental problems, we demand secure answers and distinctive limits. But there are no such. Today's science is quite clear about the problems associated with offering absolute knowledge. An answer is given in relation to conditions that are only partly known; presuppositions have a huge impact on the result, and even direct measurements imply problems. For the professional scientist this is not new, but for common man the realisation that science can offer no secure answers, is a shock. For some generations we have learnt to trust science as a reliable method of ascertaining truth and certainty. It is a new existential situation for modern man and we must re-apprehend that human life will always imply uncertainty and risk. A scientifically based world-view duped us into believing otherwise for a while, but it was an illusion. 


\subsubsection{The disadvantages of science - the other side of the coin}

The most important reason for the altered status of science is probably the obvious unsatisfactory results of science and technology that are evident today. Obviously, some of the most difficult problems of our time are the result of some technological applications of science. The negative consequences, in the form of sophisticated weapons, air pollution, poisoning of water, elimination of species and other ecological catastrophes are only too familiar and need no further elaboration in this article. Ethical problems resulting from new techniques are constantly arising. Science has lost its nimbus of intrinsical goodness.

\section{CONCLUSION}

We are moving away from a mechanistic world-view, but there is no consistent world-view ready as substitute. Why? We have identified some reasons for the fact that, despite science having changed, new science cannot serve as a foundation for a new world-view. Important reasons are that the science of today is rather different in nature and not suited for constructing a world-view. Relativity, uncertainty and chaos are not concepts and metaphors upon which a world-view can be based.

The important reasons are instead the extra-scientific ones. Science is one element in viewing the world, but is no longer the sole element and perhaps not even the strongest element in building a world-view today. Its status of science has changed. Theoretically and practically, science has lost its position as something that is self-evidently true and good.

Two paradoxes are connected to this situation. Firstly, when science made its victorious progress during the $18^{\text {th }}$ and $19^{\text {th }}$ centuries, nature was experienced as raw, chaotic and in need of domestication. Science, by imposing order, provided the answer to this need. Now, a reversed situation is being experienced. Science and technology are the threatening and chaotic forces, while nature is understood to be harmonic and well ordered in itself.

Secondly, more than ever, science is questioned and criticised. At the same time we are dependent on science more than ever before. There is no other way to the knowledge needed by a modern society. The need for science 
increases simultaneously with the realisation that science cannot give us the very security we long for. Perhaps Einstein was right after all when he said: "Religion without Science is blind. Science without Religion is lame."

\section{Works consulted}

Bohm, D \& Peat D 1987. Science, order and creativity. New York: Bantam Books.

Einstein, A 1934. Mein Weltbild. Amsterdam: Querido.

Fowler, J 1981. Stages of faith: The psychology of human development and the quest for meaning. San Fransisco: Harper \& Row.

Monod, J 1970. Le hasard et la nécessité. Paris: Éditions du Seuil. 